\title{
Clinical outcomes of 4-point scleral fixated I-piece hydrophobic acrylic equiconvex intraocular lens using polytetrafluoroethylene suture
}

This article was published in the following Dove Press journal: Clinical Ophthalmology

\author{
Nimesh A Patel \\ Parth Shah \\ Nicolas A Yannuzzi \\ Zubair Ansari \\ Jill S Zaveri \\ Nidhi Relhan \\ Basil K Williams Jr \\ Ajay E Kuriyan \\ Christopher R Henry \\ Jayanth Sridhar \\ Luis Haddock \\ Jorge A Fortun \\ Thomas A Albini \\ Janet $L$ Davis \\ Harry W Flynn Jr \\ Department of Ophthalmology, \\ Bascom Palmer Eye Institute, \\ University of Miami, Miller School \\ of Medicine, Miami, FL 33136, USA
}

Correspondence: Harry W Flynn Jr Department of Ophthalmology, Bascom Palmer Eye Institute, University of Miami, Miller School of Medicine, 900 NW 17th Street, Miami, FL 33136, USA

$\mathrm{Tel}+\mathrm{I} 3053266118$

Fax + I 3053266417

Email hflynn@med.miami.edu
Purpose: To report the visual outcomes and complications of scleral fixated intraocular lenses (IOLs) using Gore-Tex suture.

Methods: The current study is a retrospective noncomparative case series including patients who underwent scleral fixation of IOL (Akreos AO60) using Gore-Tex suture from August 2015 to March 2017 at a university teaching center. Primary outcome measures were visual acuity and complications at last follow-up.

Results: The current study included 49 eyes of 48 patients. Mean follow-up duration postsurgery was 6.9 months (range: 0.9-29.4 months). The indications for secondary IOL surgery were dislocated IOL in 16/49 (33\%), subluxed IOL in 9/49 (18\%), dislocated or subluxed crystalline lens in $9 / 49(18 \%)$, traumatic cataract in $8 / 49(16 \%)$, and complicated cataract surgery in $7 / 49$ (14\%). Mean best-corrected logMAR visual acuity improved from $1 \pm 0.7$ (20/200 Snellen equivalent) preoperatively to $0.5 \pm 0.5$ (20/63 Snellen equivalent) at last follow-up. There were no intraoperative complications noted. Early postoperative complications included significant persistent corneal edema (longer than 1 week) in 4/49 (8.2\%), ocular hypertension (intraocular pressure $\geq 25 \mathrm{mmHg}$ ) in $8 / 49(16.3 \%$ ), hypotony (intraocular pressure $\leq 5 \mathrm{mmHg}$ ) in $6 / 49$ (12.2\%), cystoid macular edema $3 / 21$ (6.1\%), IOL tilt 2/49 (4.1\%), hyphema in 2/49 (4.1\%), and vitreous hemorrhage in 5/49 (4.8\%). There was one case of recurrent retinal detachment. One patient presented with an erosion of the Gore-Tex suture through the conjunctiva resulting in a purulent scleritis 6 months after the initial surgery, and was managed with removal of the IOL, debridement, and cryotherapy. Forty-one of 49 patients completed 3-month follow-up, among which visual acuity improved, deteriorated, or remained same compared to baseline in $27 / 49$ (55.1\%), 8/49 (16.3\%), and 6/49 (12.2\%) eyes, respectively.

Conclusion: In the current study, visual acuity outcomes were generally favorable. The complications were largely transient. Significant complications included a suture-related infection, which required removal of the IOL, and a recurrence of a retinal detachment.

Keywords: Gore-Tex, secondary intraocular lens, scleral fixation, clinical outcomes

\section{Introduction}

There are currently multiple options for secondary intraocular lens (IOL) implantation. This includes anterior chamber IOLs, iris fixated posterior chamber, and scleral fixated posterior chamber IOLs. Scleral fixated IOLs have been shown to be effective as a secondary lens. ${ }^{1}$ However, there have been concerns with high rates of suture erosion with the prior use prolene suture. ${ }^{2}$ Gore-Tex (W. L. Gore \& Associates, Flagstaff, AZ, USA) is nonabsorbable monofilament suture with a greater tensile strength than prolene. Many ophthalmic clinicians are currently using Gore-Tex suture for fixation 
of secondary IOLs. ${ }^{3}$ Outcomes and complication data for this procedure have not been widely described. Short-term outcomes data have not yet allowed for the adequate assessment of potential complications. In the recent reviews on this technique, largely from a single center, there have been no reports of suture breakage or retinal detachment. ${ }^{4-6}$ The purpose of this study is to report the outcomes and complications of scleral fixated intraocular lenses using Gore-Tex suture as well as to review prior published data.

\section{Materials and methods}

The current study is a retrospective, single center, multisurgeon, noncomparative case series including patients who underwent scleral fixation of intraocular lens (Akreos AO60, Bausch and Lomb, Rochester, NY, USA) using Gore-Tex suture at the Bascom Palmer Eye Institute from August 2015 to March 2017. Surgical cases were found using current procedure terminology code for Akreos AO60 lens.

The study was conducted in accordance with the ethical standards established in the 1964 Declaration of Helsinki for research involving humans, and approved by the Institutional Review Board of the University of Miami, Miller School of Medicine. The following data were collected: age, gender, indication for surgery, pre- and postoperative best-corrected visual acuity (BCVA) and complications. Primary outcome measures were visual outcomes and complications at last follow-up.

The surgical technique has been previously described. ${ }^{3}$ The technique used in the cases where vitrectomy was done is as follows. Cases were operated on using the Alcon constellation and Alcon surgical instruments (Alcon, Fort Worth, TX, USA), and 23 or 25 gauge instrumentation was used. An infusion cannula is placed inferotemporally. Two localized conjunctival peritomies are created $180^{\circ}$ apart nasally and temporally. Four additional sclerotomies are made. Superior nasal and superior temporal sclerotomies are made $2 \mathrm{~mm}$ posterior to the limbus and $2 \mathrm{~mm}$ superior to the midline with a trocar blade. The inferior nasal and inferior temporal sclerotomies are made $2 \mathrm{~mm}$ posterior to the limbus and $2 \mathrm{~mm}$ inferior to the midline with an MVR blade. Core vitrectomy is performed. The 8-0 Gore-Tex sutures are passed first through the IOL haptics outside the eye and then the sutures are pulled through a $3.5 \mathrm{~mm}$ superior corneal wound and retrieved through the sclerotomies on each side using end grasping forceps. The Bausch and Lomb Akreos A060 IOL is folded and placed through the corneal wound into the posterior chamber of the eye. The lens can be warmed prior to the case to facilitate folding. The suture is tied in a 3-1-1 fashion temporally and then again nasally. The knots are then rotated and buried inside the sclera. The peritomies are closed using 6-0 plain gut suture. The corneal wound is closed using interrupted 10-0 nylon sutures. All patients were examined on postoperative day 1 and further follow-up was variable as determined by the individual attending surgeon. Postoperative visual acuity was recorded at all visits. Snellen visual acuity was converted into mean $\log$ MAR. Other calculations were done using statistical average and standard deviation.

\section{Results}

A total of 49 eyes of 48 patients were included in the current study. The mean age at the time of surgery was $63.0 \pm 16.2$ years old (range: $31.7-88.0$ ) and 37/49 (77\%) were men. Symptoms on presentation were decrease in vision $(92 \%)$, halos $(2 \%)$, glare $(2 \%)$ and diplopia $(4 \%)$. Indications for secondary IOL surgery included dislocated IOL in 16/49 $(33 \%)$, subluxed IOL in $9 / 49(18 \%)$, dislocated or subluxed crystalline lens in $9 / 49(18 \%)$, traumatic cataract in $8 / 49$ (16\%), and complicated cataract surgery in 7/49 (14\%).

Mean follow-up postsurgery was 6.9 months (range: 0.9-29.4 months). Mean best-corrected $\log$ MAR visual acuity improved from $1 \pm 0.7$ (20/200 Snellen equivalent) preoperatively to $0.5 \pm 0.5$ (20/63 Snellen equivalent) at last follow-up. Among 49 total eyes, 41 completed 3-month follow-up, among which visual acuity improved greater than one line, deteriorated greater than one line, or remained same compared to baseline in $27 / 49$ (55.1\%), 8/49 (16.3\%), and $6 / 49(12.2 \%)$ eyes, respectively.

There were no intraoperative complications noted. Postoperative complications included significant persistent corneal edema (longer than 1 week) in 4/49 (8.2\%), ocular hypertension (IOP $\geq 25 \mathrm{mmHg}$ ) in $8 / 49$ (16.3\%), hypotony (IOP $\leq 5 \mathrm{mmHg}$ ) in $6 / 49(12.2 \%)$, cystoid macular edema in $3 / 21$ (6.1\%), IOL tilt in 2/49 (4.1\%), hyphema in 2/49 (4.1\%), and vitreous hemorrhage in $5 / 49(4.8 \%)$ eyes. There was one case with a recurrence of a retinal detachment 12 days after placement of the secondary IOL. There was one case with an erosion of the Gore-Tex suture with a purulent scleritis. This occurred 6 months after the initial surgery and required removal of the IOL, debridement, and cryotherapy. There were no cases of postoperative endophthalmitis, uveitisglaucoma-hyphema syndrome or persistent postoperative inflammation in the follow-up period.

\section{Discussion}

The most common suture material choice for scleral fixation of IOLs has been prolene. However, due to suture-related complications, Gore-Tex suture is increasingly being used 
for this procedure, albeit off label. Gore-Tex suture material is reported to provide advantages including higher tensile strength and minimal memory, which leads to easier manipulation, and minimal inflammatory response. Recent studies have shown favorable outcomes without severe complications. Khan et $\mathrm{al}^{4-6}$ found no suture-related complications or retinal detachments.

In one retrospective series of 85 scleral fixations of a Bausch and Lomb Akreos AO60 or Alcon CZ70BD IOL using Gore-Tex suture with a mean follow-up of 325 days, outcomes were reported. Postoperative complications included hypotony $(9.4 \%)$, ocular hypertension $(7 \%)$, vitreous hemorrhage $(7 \%)$, hyphema $(2 \%)$, serous choroidal detachment ( $2 \%)$, cystoid macular edema ( $2 \%)$, and corneal edema $(1 \%)$. In the same series, no cases of postoperative endophthalmitis, suture erosion/breakage, retinal detachment, suprachoroidal hemorrhage, uveitis-glaucoma-hyphema syndrome, or persistent postoperative inflammation were reported during the follow-up period. ${ }^{1}$

In our study, there were $6(12.2 \%)$ patients with hypotony, which is similar to the rate that was prior reported. There was one case of persistent hypotony, requiring surgical exploration. Examination revealed a wound leak at a sclerotomy site. It is possible that the scleral fixation of the lens, as well as the vitrectomy, can be performed with 27-gauge instrumentation. ${ }^{5}$ This could theoretically decrease the incidence of sclerotomy leakage. Further studies would need to be performed to determine if this could decrease the rate of hypotony postoperatively.

There were two cases of lens tilt that were documented in this study. The authors suggest that one avenue to decrease lens tilt is to tie the first throw of the suture 3-1-1, alternating tightening on the nasal suture and then the temporal suture, until adequate tension is achieved and the lens is centered. After this, the second and third throw of each suture can be performed.

In the current study, a common complication in the immediate postoperative period was corneal edema. This was generally a nonpersisting condition. One case with a predisposition to endothelial disease, with pseudophakic bullous keratopathy, developed prolonged edema and required two Descemet stripping endothelial keratoplasty procedures.

There was one case with a Gore-Tex suture erosion with a subsequent purulent scleritis with Mycobacterium abscessus. This occurred 6 months after the initial surgery and required removal of the IOL, debridement of infection, and cryotherapy. The debridement was carried out with a freeze-thaw-freeze technique, and the patient was treated with oral and topical clarithromycin. The infection was treated and the patient was left aphakic. This patient had a history of retinal detachment and high myopia and was treated with a scleral buckle. The myopia and prior surgical manipulation may have contributed to incompetence of the sclera at the suture site. This case is the first known reported case to our knowledge of infectious scleritis after Gore-Tex secondary IOL surgery.

There was one case of a recurrence of retinal detachment, which has not been previously reported. This re-detachment occurred 12 days after the secondary IOL surgery in the setting of proliferative vitreoretinopathy. The patient was treated with pars plana vitrectomy, membrane peeling, endolaser, and C3F8 gas. The retina was reattached at the final follow-up.

Limitations of the current study include its retrospective nature, sample size, surgeon variability, and short duration of follow-up. It is necessary to follow the long-term outcomes of the patients from this study, as well as future cases, to be able to accurately compare complication rates to that of prolene sutured scleral fixated IOLs. Since the manifest refraction was not available for all patients, the final BCVA may not represent the true BCVA.

\section{Conclusion}

This study provides short-term outcomes data for the use of scleral fixated IOLs with Gore-Tex suture. This series adds to the current literature, which has been largely from a single center, $^{3-6}$ further data on the safety profile of this surgical technique using an off-label suture material for secondary IOL surgery. The acuity outcomes were generally favorable. This study illustrates complications after this procedure are largely transient and include ocular hypertension, hypotony, wound leak, and lens tilt in the early follow-up course. In this study, there was one patient with a Gore-Tex suture-related infection which required removal of the IOL and once case of recurrent retinal detachment, neither of which have been previously reported.

\section{Informed consent}

All patients were treated with informed consent. Consent for the study was not necessary due to confidentiality and institutional review board requirements.

\section{Acknowledgments}

This study is supported in part by NIH Center Core Grant P30EY014801, Research to Prevent Blindness Unrestricted Grant, and Department of Defense (DOD-Grant\#W81XWH13-1-0048). The abstract of this paper was presented at ARVO 2017, Retina Society 2017, American Society for Cornea and 
Refractive Surgeons 2018 as a poster presentation/conference talk with interim findings.

\section{Disclosure}

Dr Fortun works with DORC. He is the consultant for Alcon and DORC outside the submitted work. Dr Albini is the consultant for Beaver Visitec, Abbvie, Bausch and Lomb, Eleven Biotheraputetics, DORC, Allergan, Alcon, Santen, Clearside, UCB Corp, Genentech/Roche, outside the submitted work. Dr Flynn Jr reports grants from NIH Center, during the conduct of the study. The authors report no other conflicts of interest in this work.

\section{References}

1. Wagoner MD, Cox TA, Ariyasu RG, Jacobs DS, Karp CL, American Academy of Ophthalmology. Intraocular lens implantation in the absence of capsular support: a report by the American Academy of Ophthalmology. Ophthalmology. 2003;110(4):840-859.
2. Vote BJ, Tranos P, Bunce C, Charteris DG, da Cruz L. Long-term outcome of combined pars plana vitrectomy and scleral fixated sutured posterior chamber intraocular lens implantation. Am J Ophthalmol. 2006;141(2):308-312.

3. Khan MA, Gupta OP, Smith RG, et al. Scleral fixation of intraocular lenses using Gore-Tex suture: clinical outcomes and safety profile. $\mathrm{Br} J$ Ophthalmol. 2016;100(5):16.

4. Khan MA, Gerstenblith AT, Dollin ML, Gupta OP, Spirn MJ. Scleral fixation of posterior chamber intraocular lenses using gore-tex suture with concurrent 23-gauge pars plana vitrectomy. Retina. 2014;34(7): $1477-1480$.

5. Khan MA, Samara WA, Gerstenblith AT, et al. Combined pars plana vitrectomy and scleral fixation of an intraocular lens using gore-tex suture: One-Year Outcomes. Retina. 2018;38(7):1377-1384.

6. Khan MA, Gupta OP, Pendi K, et al. Pars plana vitrectomy with anterior chamber versus gore-tex sutured posterior chamber intraocular lens placement: long-term outcomes. Retina. Epub 2018 Jan 16.
Clinical Ophthalmology

\section{Publish your work in this journal}

Clinical Ophthalmology is an international, peer-reviewed journal covering all subspecialties within ophthalmology. Key topics include: Optometry; Visual science; Pharmacology and drug therapy in eye diseases; Basic Sciences; Primary and Secondary eye care; Patient Safety and Quality of Care Improvements. This journal is indexed on

\section{Dovepress}

PubMed Central and CAS, and is the official journal of The Society of Clinical Ophthalmology (SCO). The manuscript management system is completely online and includes a very quick and fair peer-review system, which is all easy to use. Visit http://www.dovepress.com/ testimonials.php to read real quotes from published authors. 